\title{
MELATONIN AND MONOAMINERGIC SYSTEM - BEHAVIOURAL ASPECTS
}

\author{
S.E. Voiculescu ${ }^{1 *}$, A. Rosca ${ }^{1,2 *}$, C.M.D. Zahiu' ${ }^{1}$ C. Badiu ${ }^{3}$, A.M. Zagrean ${ }^{1}$ \\ ${ }^{1}$ Department of Functional Sciences, Discipline of Physiology and Fundamental Neuroscience, \\ "Carol Davila" University of Medicine and Pharmacy, Bucharest, Romania \\ 2 "Victor Babes" National Institute of Research-Development in the Pathology Domain, \\ Bucharest, Romania \\ ${ }^{3}$ Department of Endocrinology, "Carol Davila” University of Medicine and Pharmacy, \\ "C.I. Parhon” National Institute of Endocrinology, Bucharest, Romania
}

${ }^{*}$ These authors contributed equally to this study.

\begin{abstract}
Melatonin, the hormone synthesized mainly by the pineal gland, is a key member of the complex monoaminergic signaling system, and a circadian regulator with pleiotropic functions. This ubiquitary lipophilic and hydrophilic molecule acts both at cellular and subcellular level, exerting anti-inflammatory, anti-oxidative and anti-apoptotic activities, extremely important in the nervous system, given its high vulnerability to oxidative injury. Melatonin deprivation and the consecutive chronodisruption are associated with multiple behavioural abnormalities, psychiatric disorders and neurodegenerative diseases. The present review summarizes the available information concerning the link between melatonin, monoaminergic neurotransmission and the pathophysiological bases of these conditions.
\end{abstract}

Keywords: melatonin, serotonin, norepinephrine, dopamine, neuroprotection, anxiety, depression, memory, aggression

\section{INTRODUCTION}

Melatonin is an endogenous indoleamine mainly produced by the pineal gland with a circadian rhythmicity. In the past years, this hormone has been found in the highlight of medical research, due to its multiple roles in human and animal physiology: circadian regulator (1-6), antioxidant (7-17), sleep inducer (18-24), anti-carcinogenic (25-27), immune-modulator (28-36), neuroprotection (37-40).

Melatonin has an extensive role in the physiology and physiopathology of the nervous system, both by its remarkable antioxidant properties and functional networking with the monoaminergic neurotransmission system.

Most of melatonin is of pineal origin, but there seem to be also other central nervous system sources. These sources are not known, but mRNA for arylalkylamine $\mathrm{N}$-acetyltransferase (AANAT) and hydroxyindole-O-methyltransferase (HIOMT), key enzymes in the melatonin synthesis, have been identified in the brain tissue of rats (41). The astrocytes of rats and the human glioma C6 cell line have been found to produce melatonin under in vitro conditions (42). Melatonin level in the cerebrospinal fluid is much higher than its maximum plasmatic one, and studies in sheep sustain a direct release of melatonin in the cerebrospinal fluid of the third ventricle (43). Several studies point the role of melatonin in different behaviours such as learning, anxiety behaviour, depression, stress response (41-52), memory (53) and pain perception (55-57). Abnormalities of melatonin secretion are associated with different psychiatric disorders in humans (bipolar disorder, depression, bulimia, an- 
orexia, schizophrenia, panic attack, and obsessive compulsive disorder), but its involvement in the pathophysiology of these diseases has not being clearly established (54).

Melatonin was shown to be neuroprotective to both fetal and adult brain (70-77), especially by its powerful antioxidant action. By this effect, melatonin seems to be involved in aging, aging-related nervous system pathology, neurodegenerative disorders and neuropsychiatric diseases.

\section{Melatonin and neuroprotection}

A common pathophysiological mechanism of neuropsychiatric diseases is increased brain inflammatory response caused by exposure to proinflammatory agents and accumulation of degenerated neurons, oxidized proteins, lipid peroxidation or glycated products in the adult brain (58). These oxidative stress processes are also involved in the pathophysiology of neurodegenerative diseases (Alzheimer's disease, Parkinson's disease, multiple sclerosis, lateral amyotrophic sclerosis, Huntington corea and tardive dyskinesia) (59). Nervous system cells produce a high quantity of free radicals mainly due to the biochemical composition of the neurons that contain unsaturated lipids, with a very intense sensitivity to peroxidation and other oxidative processes (60). Recent research has shown a particular sensitivity of nervous system cells to oxidative stress, free ROS triggering apoptosis in both glial cells and neurons (61).

Melatonin, by melatonin radicals, exerts its antioxidant properties by direct scavenge of hydroxyl radical (HO.), superoxide anion radical $\left(\mathrm{O}_{2^{-}}\right)$, hydrogen peroxide $\left(\mathrm{H}_{2} \mathrm{O}_{2}\right)$, nitric oxide (NO.) and peroxynitrite anion (ONOO-) (62). Moreover, melatonin metabolites which result during ROS neutralisation processes are even more powerful antioxidant agents $(63,64)$. Except for this direct role, melatonin exerts an indirect one through enhancing antioxidant enzymes activity (glutathione peroxidase, superoxide dismutase, catalase) and glutathione synthesis in the cells $(65,66)$. Melatonin also contributes to mitochondrial homeostasis, lowers free radicals generation at this level and enhances ATP production, by direct stimulation of I and IV enzymatic complexes. This is referred as the free radical avoidance effect of melatonin (67).

A comprehensive body of evidence suggests the neuroprotective effect of melatonin, by virtue of its anti-inflammatory, anti-oxidant and anti-apoptotic effects. Fetal and neonatal brain neuroprotection efficacy of melatonin has been reported in several studies conducted in animals. Its administration af- ter 10 minutes following a hypoxic-acidemic episode, lowered apoptosis, inflammation and gliosis in the brain of sheep fetuses (70). Melatonin treatment before and during temporary fetal asphyxia stabilized blood-brain barrier and reduced free hydroxyl radicals, lipid peroxidation and apoptosis in the fetal brain (71).

Maternal melatonin administration reduced fetal asphyxia, enhanced neurodevelopment and lowered cerebral damage and oxidative stress in an animal model of intrauterine growth restriction in newborn lambs (72). Melatonin was also proven to augment neuroprotection, when combined with therapeutic hypothermia against transient hypoxicischemic brain injury in a piglet model of perinatal asphyxia (73). Systemic melatonin administration in newborn rats with intracerebral haemorrhage showed a positive effect on the consecutive cerebral atrophy, cognitive and sensorimotor dysfunctions (74). In asphyxiated human newborns melatonin showed a significant decrease in plasma levels of nitric oxide metabolism end products (nitrate/ nitrite) and lipid peroxidation (75).

As an effective antioxidant and neuroprotective molecule, melatonin synthesis may be induced by a negative feedback loop triggered by high oxidative stress or other stresses. Stress-induced melatonin production has been observed in rat pancreas (76) and in human cerebrospinal fluid after brain trauma (77).

\section{Functional relationship between melatonin and central monoaminergic system}

Melatonin influences normal function of the central nervous system, through a fine interaction with central neurotransmitters, especially the monoaminergic ones: serotonin, norepinephrine and dopamine.

\section{Melatonin and serotonin}

First, serotonin has a biosynthetic relationship with melatonin, as the latter is a tryptophan derivative ( $\mathrm{N}$-acetyl-5-methoxytryptamine), in a pathway that has serotonin as an intermediate product. Melatonin synthesis is regulated by the suprachiasmatic nucleus $(\mathrm{SCN})$ of the hypothalamus that receives serotonergic afferent fibers from the median nucleus of the mesencephalon $(78,79)$. It appears that serotonin modulates the manner in which light influences the suprachiasmatic nucleus, by controlling glutamate release at the level of the retinohypothalamic tract (80). The administration of a serotonin agonist determines variations in the su- 
prachiasmatic nucleus rhythm (81). The molecular mechanism by which serotonin influences SCN is not known, but an interesting theory points that serotonin raises $\mathrm{K}+$ influx at postsynaptic level in a population of neurons in the nucleus (82). Another study shows a presynaptic influence of serotonin (83).

It seems that serotonin synchronises circadian rhythms, as similarly the light does, but it works only under light conditions, in the dark/night its administration having no action on Clock genes expression (84). This effect may be explained by a circadian manner of expression of the serotonergic receptors (85). Interestingly, melatonin has an inhibitory role on the serotonin secreting raphe nuclei, via the melatonin type 1 receptor $\left(\mathrm{MT}_{1}\right)$ (86).

\section{Melatonin and norepinephrine}

SCN is regulating melatonin secretion via a multisynaptic pathway. First of all, it sends fibers to the superior thoracic segments of the spinal cord that in turn sends fibers to the $\mathrm{C}_{1}$ ganglion of the paravertebral sympathetic chain. Postganglionic fibers reach the pinealocytes and influence them through a noradrenergic synapse (87). In darkness, noradrenaline release in the synaptic cleft is enhanced and determines a raise in intracellular cAMP levels by acting on beta1 receptors, leading to AANAT synthesis and melatonin secretion $(88,89)$. Melatonin pineal synthesis depends on this rate-limited enzyme that catalyses serotonin $\mathrm{N}$-acetylation (90).

There are other mechanisms by which noradrenaline controls melatonin secretion: insulin enhances melatonin synthesis and AANAT expression, whilst substance $\mathrm{P}$ (for which pinealocytes have receptors) inhibits AANAT synthesis $(91,92)$.

\section{Melatonin and dopamine}

Dopamine is the precursor of norepinephrine. Secretory cells of the pineal gland have a high expression of $\mathrm{D}_{4}$ dopaminergic receptors, and their expression seems to be modulated by light (93).

Melatonin controls dopamine synthesis in certain brain regions like the hypothalamus, tubuloinfundibular region and the ventral hippocampus (94). Some studies show that melatonin might have a direct effect on dopaminergic receptors producing a raise in $\mathrm{D}_{2}$ receptor expression in the striated nucleus of the rat (95). Localisation of the $\mathrm{MT}_{1}$ and $\mathrm{MT}_{2}$ receptors at the level of the SCN overlaps with dopaminergic receptors in the hippocampus, cortex and hypothalamus (96-98). It has been demonstrat- ed that dopaminergic receptors have a circadian manner of expression, being low during light conditions (99). Melatonin shows a protective role in medication induced dopaminergic motor dysfunctions in rats $(100,101)$.

\section{Monoaminergic system involvement in neurodegenerative diseases}

There are several studies pointing the involvement of the monoaminergic system and associated areas (raphe nuclei, hippocampus and locus coeruleus) in the pathophysiology of neurodegenerative diseases, including Alzheimer's disease (AD) $(102,103)$, supporting the association of depression in these diseases $(104,111,112)$.

A low melatonin level in the cerebrospinal fluid has been found in AD patients (68), correlated negatively with the disease severity (69). Also, brain and cerebrospinal levels of norepinephrine and its metabolite (3-metoxy-4-hydroxyphenylglycol) have been found low in patients with $\mathrm{AD}$ compared to healthy controls $(105,106)$.

Post-mortem determinations of serotonin in Alzheimer's patients have shown its low levels in both cerebral tissue and cerebrospinal fluid (107, 108), negatively correlated with the severity of the disease (109). A significant loss of 5-HT neurons in the raphe nuclei has been found $(113,114)$ and 5 -HT is decreased in the brain of depressed AD patients (115). Extrapyramidal symptoms are present in up to $30 \%$ of AD patients, and also when Parkinson's and Alzheimer's diseases overlap (110), sustaining the coexistence of dopaminergic dysfunction.

Parkinson's disease degeneration targets the nigrostriatal dopaminergic system (116), but serotonin and noradrenaline systems have also been shown to be involved (117). Thus, Parkinsonian tremor is accompanied with serotonergic impairment (118) and the Parkinson's disease associated psychiatric disorders (dementia and depression) have a direct relationship to the monoaminergic dysfunction, supported by the therapeutic use of monoamine oxidase inhibitors (MAOI) in Parkinson's associated depression (119).

\section{Melatonin and the pathophysiological basis of depressive disorders}

Pathophysiological mechanisms of depressive disorders are not entirely known but there is enough evidence that points the contribution of genetic, environmental, anatomic and functional dysregulations of the central nervous system. There are two 
neuroanatomical pathways involved: the first one includes the amygdala, mediodorsal nucleus of the thalamus, and prefrontal cortex, and the second one includes strium and globus pallidus (120).

The neurobiological hypothesis of depression shows an abnormal interaction between the three monoaminergic systems (serotonin, norepinephrine and dopamine). The noradrenergic neurons have a functional intermediate position between the serotonergic and dopaminergic ones, controlling the amplitude and rate of action potentials of the dopaminergic neurons in the ventral tegmental area, an area crucially involved in mood (120).

Serotonin deficiency seems to be the most important pathophysiological mechanism, this idea being supported by the intensive use of selective serotonin reuptake inhibitors (SSRI) in depression treatment. There are 14 subtypes of serotonin receptors (121), from which 5-HT1a, highly expressed in the cortex, limbic system and hippocampus, being the most important one in depression pathogenesis (122).

Nocturnal melatonin levels are low in subjects with major depressive disorder $(123,124)$ and also in people with seasonal (125) and melancholic depression (126). Major depressive disorder is associated with circadian rhythm abnormalities. Li et al. have shown dysregulations in the synchronisation activity of the internal biological clocks, day/light succession and abnormal clock genes expression in major depressive disorder (MDD) (127).

$\mathrm{MT}_{1}$ receptors knock-out mice show a low mobility in forced swim and tail suspension despair tests that in depressive behaviour test in lab animals. These results may be related to neurobiological and behavioural abnormalities, corresponding to human melancholic depression (128). Melatonin's involvement in depression is supported by the fact that agomelatin, a non-selective $\mathrm{MT}_{1}$ and $\mathrm{MT}_{2}$ receptors agonist and 5-HT2c serotonin receptors selective agonist, has a high efficacy in depressive disorders treatment, measured by clinical psychiatric scores (129-132).

Shahnaz et al. (2012) monitored morning and nocturnal levels of melatonin in patients with MDD. Their data showed that nocturnal serum melatonin levels in depressed patients were lower than in controls. Also, the peak melatonin phase in the depressed patients was reached with a delay, compared with controls. All these data sustain that melatonin deficiency may be among the factors involved in depression incidence in patients with MDD (133). Also, a study on acute multiple sclerosis patients with concomitant MDD showed that the nocturnal melatonin peak occurred 77 minutes later than in patients without depression (134).

The relation between serotonergic neurotransmission and melatonin, other than the biosynthetic pathway connection, is shown by the rise in cerebral serotonin levels after melatonin administration (135).

Regarding the genetic factors involved in depression, it is hard to point one specific gene but some studies have identified 5-HTT and brain-derived neurotrophic factor (BDNF) as candidates. 5-HTT gene codes the serotonin reuptake inhibition at presynaptic level. Caspi et al. have identified the presence of a mutated allele of this gene to have a higher risk of depression following stressful events (136).

BDNF is mainly expressed in the nervous system, especially in the cortex and hippocampus. Egan et al. (2003) identify a single nucleotide polymorphism of the BDNF gene in which a valinemethionine substitution at codon 66 leads to depression in stressful circumstances (137). There are also studies in rats that associate depression with low BDNF expression in the hippocampus, and anti-depressive medication determines normalization of BDNF levels (138). BDNF expression in the adult brain is highest at the level of the hippocampus, amygdala and hypothalamus (139), areas involved in depression and anxiety disorders.

Kaufman et al. (2006) identify an interaction between three factors concurring to depression pathophysiology, the same short allele of 5-HTT gene as in the previously mentioned study, BDNF gene polymorphism and a stressful event (140). Melatonin positively modulates BDNF expression in the hippocampus and the cerebellum. This effect was investigated in a chronic sleep deprivation model in rats that follows the level of cognitive deficit (139). There are no studies showing the direct connection between melatonin levels and 5-HTT gene expression, but investigations in this direction are surely needed, considering the important functional link between melatonin and serotonin.

Melatonin deprivation in pregnant rats, in the second part of their pregnancy leads to depressivelike behaviour when assessed by the forced swim test, but with a normal appearance of the tail suspension test in adult male offspring (141). Because forced swim test is dependent on dopamine signaling solely, while tail suspesion test on both dopamine and serotonin, the authors concluded that melatonin deprivation in dams leads to abnormalities in serotonin secretion and/or signaling in adult offspring. This study points a probable prenatal 
cause for depression, that may concur with the previousely mentioned pathophysiological cues.

Increasing amounts of data suggest that chronic inflammation is an important factor in the pathogenesis of depression (142). Proinflammatory cytokines activate indolamine 2, 3-dioxygenase (IDO), an enzyme that catabolizes tryptophan, the precursor of serotonin, impairing peripheral and cerebral serotonin synthesis (143) and producing neurotoxic metabolites. 3-hydroxykynurenine (3-OH-KYN) is one of these neurotoxic metabolites that initiate neuronal apoptosis by inducing reactive oxygen species production (144).

\section{Melatonin and memory}

Areas of the central nervous system involved in memory are the prefrontal cortex and amygdala for the long-term memory and hipoccampus, enthorhinal and parietal cortex for both of them (146). Short-term and long-term memories have different physiological mechanisms, involving specific monoaminergic neurotransmitters. Rat studies developed by Vianna et al. (2015) show that an infusion of a $D_{1}$ receptor antagonist substance stimulates short-term memory. Administration of a $D_{1}$ receptor agonist or a 5-HT1A one inhibits shortterm memory without affecting long-term memory. Noradrenaline facilitates long-term memory, having no influence on the short-term one (145).

Clock gene expression seems to be important in memory. Distruction of the SCN or induced abnormalities of the circadian system by inappropriate light exposure, determine long-term memory impairment (147). Mice with clock genes mutations have abnormal hippocampus-dependent memory function $(148,149)$. Melatonin itself has been shown to have a role in short-term memory. Argyrou et al. have investigated rats response to social olfaction memory, before and after intraventricular melatonin administration. Recognition time was shorter in the melatonin treated group than in the luzindol (selective $\mathrm{MT}_{1}$ receptor antagonist) treated one (53). However,studies regarding melatonin involvement in memory are contradictory, as one shows that intra-amygdalian injection of melatonin in rats leads to alterations in spatial memory (150). Amir et al. (1999) have used c-Fos gene product determination for cellular activity measurment, showing that cortical areas involved in olfaction express the protein in a circadian manner. Also, olfactory stimulation leads to an enhanced c-Fos expression in the SCN (151). Granados-Fuentes et al. (2006) identified an intrinsec regulation system at olfactory bulb level and showed that circadian responsivity depends on circadian rhythm, being higher at night and lower during daytime in mice, rats and humans (152).

\section{Melatonin and anxiety behaviour}

Anxiety disorders represent the most common pshychiatric pathology in adults. This group is very heterogenous, but all subtypes encounter serotonergic and noradrenergic abnormalities and also disregulations of the hypothalamic-hypophysealcorticosuprarenal and hypothalamic-hypophysealthyroid axes. There is also a documented genetic predisposition of anxiety disorders, based on studies involving twins. If one twin has an anxiety disorder, the other one has 50\% higher risk to develop one in the future, compared with the general population (153).

Serotonergic pathways involved in anxiety (dorsal raphe nucleus) innervate the amygdala and prefrontal cortex, leading to an enhancement of the avoiding and run behaviour when facing a stress. Noradrenergic system (locus coeruleus) and dopaminergicone sensitize autonomic activation and vigilence as threat responses (154).

Melatonin has an anxiolytic effect (155). Anxious behaviour has been linked with melatonin deprivation in adult Wistar rats. El Mrabet et al. (2012) point that pinealectomy in adult rats leads to both anxious and depressive behaviour, and that melatonin administration cancels these effects (156). Melatonin enhances the anxiolytic effect of diazepam, when symultaneously administered (157) and modifies anxiety behavioral tests response (forced swim test) under long-term administration (158). Apparently, the effect of melatonin on anxiety is modulated by GABA central release. A positive correlation between brain melatonin levels and GABA transmission has been identified in vivo and in vitro $(159,160)$.

Clock circadian genes malexpression has been linked with anxiety. Mutant Clock gene mice show a higher anxiety level, when behaviourally assesed using open field test and elevated plus maze test (161). There is only one study regarding anxiety disorders in humans, in which 13 genes mutations were investigated. The study included 321 patients and 653 healthy controls and identified 3 possible anxiety- related genes: BCL-2, DRD-2 and PAWR (162). BCL-2 (B-cell CLL/Lymphoma 2) codes for a protein that has key functions in the central nervous system, its most important one being apoptosis regulation. Melatonin modulates BCL-2 expression in different organs (liver, B cells), but there are no studies using nervous system cells $(163,164)$. 
BCL-2 expression is low in anxiety disorders (165). DRD2 gene (dopamine receptor gene 2) has been shown to be induced by light in the retina and its mutations are strongly associated with anxiety disorders. There is no study showing a direct relationship between melatonin and DRD2 gene expression, but signaling mediated by the dopamine D2 receptor potentiates circadian regulation by CLOCK/BMAL1 (166). Clock protein is the central molecule of the circadian system, a transcription activator regulated by melatonin (167). Clock gene abnormalities have been associated with mood disorders and anxiety in several studies $(168,169)$.

\section{Melatonin and aggressive behaviour}

Aggressive behaviour is primitive, but highly conserved on phylogenetic scale, including humans. It can be regulated by nervous and humoral mechanisms. Humoral regulation has been studied intensively, and there are several possible involved molecules: testosterone (170), progesterone (171), estrogens (172), melatonin (173), vasopressin (174), cortisol (175) and ghrelin (176).

Aggression is abolished in castrated males, this pointing a higher importance of sex hormones in its physiology (177). There are also studies showing that both central serotonin depletion (170) and high melatonin level enhances aggression $(178,179)$. It was recently suggested that melatonin could mediate adrenal gland regulation of aggressive behaviour, by increasing adrenal dehydroepiandrosterone release (180)

\section{CONCLUSIONS}

Melatonin is an important neuromodulator in central nervous system, which acts on any of the three monoaminergic systems and on complex intricated pathways by which it depends upon eachother. Regulation of the melatonin secretion is rather simple, being enhanced by darkness and lowered by light, blue light having the most powerful inhibitory effect. This makes it very sensitive to external environment conditions in the era of blue light emitting electronic devices, depression and anxiety.

The hormone is involved in many types of behaviours such as depression, aggression, memory and anxiety. Its importance is crucial for the normal functioning of the central nervous system. The association of melatonin deprivation with behavioral abnormalities might be caused by the direct lack of modulation and abnormal functioning of the central monoaminergic circuits, but also by the resulted oxidative stress, confusing circadian inputs and gene expression abnormalities in the brain. Melatonin provides important antioxidant activity, inhibition of apoptotic processes and immunomodulatory effect. The effects of circadian system disruption have not been studied enough compared with their outcome in central nervous system physiology and pathology. Melatonin seems to be involved in the pathophysiology of both neuropsychiatric and neurodegenerative diseases, and the prevalence and/or severity of these diseases may have a direct link with unhealthy general chronodisrupting behaviours that modern society adopts.

\section{Acknowledgments}

This paper is partly supported by the Sectorial Operational Programme Human Resources Development (SOPHRD), financed by the European Social Fund and the Romanian Government under the contract number POSDRU 141531.

\section{REFERENCES}

1. Zimmerman N.H., Menaker M. Neural connections of sparrow pineal: role in circadian control of activity. Science 1975; 190(4213):477-9.

2. Cajochen C., Krauchi K., Wirz-JusticeA. Role of Melatonin in the Regulation of Human Circadian Rhythms and Sleep; Journal of Neuroendocrinology, 2003, Vol. 15, 432-437

3. Lynch H.J., Wurtman R.J., Moskowitz M.A., Archer M.C., Ho M.H. Daily rhythm in human urinary melatonin. Science. 1975;187:169-71

4. Turek F.W., McMillan J.P., Menaker M. Melatonin: effects on the circadian locomotor rhythm of sparrows. Science 1976; 194(4272): $1441-3$

5. McArthur A.J., Gillette M.U., Prosser R.A. Melatonin directly resets the rat suprachiasmatic circadian clock in vitro. Brain Res 1991; 565(1): 158-61;
6. Liu C., Weaver D.R., Jin X., et al. Molecular dissection of two distinct actions of melatonin on the suprachiasmatic circadian clock. Neuron 1997; 19(1):91-102.

7. Hardeland R., Reiter R.J., Poeggeler B., Tan D.X. (1993) The significance of the metabolism of the neurohormone melatonin: Antioxidative protection and formation of bioactive substances. Neurosci Biobehav Rev. ; 17 : 347-57.

8. Hardeland R., Balzer I., Poeggeler B., Fuhrberg B., Uria H., Bahrmann G., Wolf R., Meyer T.J., Reiter R.J. (1995) On the primary functions of melatonin in evolution: mediation of photoperiodic signals in unicell, photoxidation, and scavenging of free radicals. J Pineal Res; 18 : 104-11

9. Allegra M., Reiter R.J., Tan D.X., Gentile C., Tesoriere L., Livrea M.A. (2003) The chemistry of melatonin's interaction with reactive species. J Pineal Res.; 34: 1-10. 
10. Reiter R.J., Tan D.X., Osuna C., Gitto E. (2000c) Actions of melatonin in the reduction of oxidative stress: A review. J Biomed Sci.; $7: 444-58$

11. Rodriguez C., Mayo J.C., Sainz R.M., Antolinil, Herrera F., Martin V., Reiter R.J. Regulation of antioxidant enzymes: a significant role for melatonin. J Pineal Res 2004; $36: 1-9$

12. Urata Y., Honma S., Goto S., Todoroki S., lida T., Cho S., Honma K., Kondo T. Melatonin induces gamma-glutamylcysteine synthetize mediated by activator protein-1 in human vascular endothelial cells. Free Radic Bio Med 1999; 27:838-847

13. Gitto E., Tan D.X., Reiter R.J., Karbownik M., Manchester L.C., Cuzzocrea S., Fulia F., Barberi I. (2001a) Individual and synergistic actions of melatonin: Studies with vitamin E, vitamin C, glutathione and desferoxaminein liver homogenates. J Pharm Pharmacol.; 53: 1393-401.

14. Mayo J.C., Sainz R.M., Antolin I., Herrera F., Martin V., Rodriquez C. (2002) Melatonin regulation of antioxidant enzyme gene expression. Cell Mol Life Sci.; 59: 1706-13

15. Mayo J.C., Tan D.X., Sainz R.M., Lopez-Burillo S., Reiter R.J. (2003) Oxidative damage to catalase induced by peroxyl radicals: Functional protection by melatonin and other antioxidants. Free Radic Res.; 37: 543-53

16. Acuna-Castroviejo D., Escames G., Carozo A., Leon J., Khaldy H., Reiter R.J. (2002) Melatonin, mitochondrial homeostasis and mitochondrial-related diseases. Curr Top Med Chem.; 2:133-52

17. Okatani Y., Wakatsuki A., Reiter R.J., Miyahara Y. (2003a).Acutely administered melatonin restores hepatic mitochondrial physiology in old mice. Int J Biochem Cell Biol.; 35: 367-75

18. Petrie K., Conaglen J.V., Thompson L., Chamberlain K. Effect of melatonin on jet lag after long haul flights. Br Med J. 1989; 298:705-707.

19. Herxheimer A., Petrie K.J. Melatonin for prevention and treatment of jet lag. Cochrane Database Syst Rev. 2002; 2: CD001520.

20. Riemann D., Klein T., Rodenbeck A., et al. Nocturnal cortisol and melatonin secretion in primary insomnia. Psychiatry Res. 2002; 113:17-27.

21. Pavel S., Goldstein R., Petruscu M. Vasotocin, melatonin and narcolepsy: possible involvement of the pineal gland in its patho-physiological mechanism. Peptides. 1980; 1:281-284.

22. Jan J.E., Espezel H., Appleton R.E. The treatment of sleep disorders with melatonin. Dev Med Child Neurol 1994; 36:97-107

23. Smits M.G., Nategaal E.E., van der Heijden J., et al. Melatonin for chronic sleep onset insomnia in children: a randomized placebo-controlled trial. J Child Neurol 2001; 16:86-92.

24. Dodge N.N., Wilson G.A. Melatonin for treatment of sleep disorders in children with developmental disabilities. J Child Neurol 2001; 16:581-4.

25. Karasek M., Fraschini F. Is there a role for the pineal gland in neoplastic growth? In: Fraschini, F, Reiter, RJ, ed. Role of Melatonin and Pineal Peptides in Neuroimmunomodulation. New York, NY: Plenum; 1991:243-251.

26. Blask D.E., Cos S., Hill S.M., Burns D.M., Lemus-Wilson A., Grosso D.S. Melatonin action on oncogenesis. In: Fraschini, F, Reiter, RJ, eds. Role of Melatonin and Pineal Peptides in Neuroimmunomodulation. New York, NY: Plenum; 1991:233-240.

27. Anisimov V.N., Alimova I.N., Baturin D.A., et al. The effect of melatonin treatment regimen on mammary adenocarcinoma development in HER-2/neu transgenic mice. Int. J. Cancer. 2003; 103:300-305

28. Guerrero J.M., Reiter R.J. Melatonin-immune system relation-ships. Curr Top Med Chem 2002; 2:167-79.

29. Withyachumnarnkul B., Nonaka K.O., Santana C., et al. Interferon-gamma modulates melatonin production in rat pineal glands in organ culture. J Interferon Res 1990; 10: 403-11

30. Petrie K., Dawson A.G., Thompson L., Brook R. A double-blind trial of melatonin as a treatment for jet lag in international cabin crew. Biol Psychiatry. 1993; 33:526-530.

31. Wetterberg $L$. The relationship between the pineal gland and the pituitary-adrenal axis in health, endocrine and psychitric conditions. Psychoneuroendocrinology. 1983; 8:75-80
32. Maestroni G.J.M., Conti A., Pierpaoli W. Role of the pineal gland in immunity: circadian synthesis and release of melatonin modulates the antibody response and antagonizes the immunosuppressive effect of corticosterone. J Neuroimmunol. 1986; 13:19-30.

33. Mori W., Aoyama H., Mori N. Melatonin protects rats from injurious effects of a glucocorticoid, dexamethasone. Jpn J Exp Med. 1984; 54:255-261

34. Sutherland E.R., Martin R.J., Ellison M.C., Kraft M. Immunomodulatory effects of melatonin in asthma. Am J RespirCrit Care Med. 2002; 166:1055-1061

35. Chen Q., Wei W. Effects and mechanisms of melatonin on inflammatory and immune responses of adjuvant arthritis rat. IntImmunopharmacol. 2002; 2:1443-1449

36. Lissoni P., Vogore L., Rescaldini R., et al. Neuroimmunotherapy with low-dose subcutaneous interleukin-2 plus melatonin in AIDS patients with CD4 cell number below $200 / \mathrm{mm}^{3}$ : a biological phase- II study. J BiolRegulHomeost Agents. 1995;9:155-158.

37. Manev H., Uz T., Kharlamov A., Joo J.Y. Increased brain damage after stroke or excitotoxic seizures in melatonin-deficient rats. FASEB J. 1996;10:1546-1551.

38. Li X.J., Zhang L.M., Gu J., Zhang A.Z., Sun F.Y. Melatonin decreases production of hydroxyl radical during cerebral ischemiareperfusion. Zhongguo Yao Li XueBao. 1997; 18:394-396.

39. Cho S., Joh T.H., Baik H.H., Dibinis C., Volpe B.T. Melatonin administration protects $\mathrm{CA} 1$ hippocampal neurons after transient forebrain ischemia in rats. Brain Res. 1997; 755:335-338.

40. Kilic E., Ozdemir Y.G., Bolay H., Kelestimur H., Dalkara T. Pinealectomy aggravates and melatonin administration attenuates brain damage in focal ischemia. J. Cereb. Blood Flow MeTable. 1999; 19:511-516.

41. Stefulj J., Hörtner M., Ghosh M., Schauenstein K., Rinner I., Wölfler A., Semmler J., Liebmann P.M. Gene expression of the key enzymes of melatonin synthesis in extrapineal tissues of the rat. J Pineal Res. 2001 May; 30(4):243-7

42. Liu Y.J., Zhuang J., Zhu H.Y., Shen Y.X., Tan Z.L., Zhou J.N. Cultured rat cortical astrocytes synthesize melatonin: absence of a diurnal rhythm. J Pineal Res. 2007 Oct; 43(3):232-8

43. Longatti P., Perin A., Rizzo V., Comai S., Giusti P., Costa C.V. Ventricular cerebrospinal fluid melatonin concentrations investigated with an endoscopic technique. J Pineal Res. 2007 Mar; 42(2):113-8

44. Arendt J. Melatonin, circadian rhythms and sleep. New England J Med. 2000; 343:1114-1116

45. Wirz-Justice. Treatment tools in chronobiology. Rev Med Interne. 2001 Jun; 22 Suppl 1:37s-38s.

46. Borjigin J., Li X., Snyder S. H., 1999. The pineal gland and melatonin: molecular and pharmacologic regulation. Annu Rev Pharmacol 395365

47. Brzezinski A., 1997 Melatonin in humans. New Engl J Med 336186195

48. Masana M.I., Dubocovich M.L., 20, 2001 Melatonin receptor signaling: finding the path through the dark. Science STKE pe39.

49. Vanecek J., 1999 Inhibitory effect of melatonin on $\mathrm{GnRH}$ induced $\mathrm{LH}$ release. Rev Reprod 46772

50. Krause D.N., Dubocovich M.L., 1990. Regulatory sites in the melatonin system of mammals. Trends Neurosci 13464470;

51. Naranjo-Rodriguez E.B., Orsornio A., Ortiz, E. Hernandez-Avitia, V. Mendoza-Fernandez, A. Escobar, 2000. Anxiolytic-like actions of melatonin, 5-methoxytryptophan, 5-hydroxytryptophol and benzodiazepines on a conflict procedure. Prog Neuropsychopharmacol Biol Psychiatry 24117129

52. Loiseau F., Bihan C.L., Hamon M., Thiebot M.H., 2006. Effects of melatonin and agomelatine in anxiety-related procedures in rats: Interaction with diazepam. Eur Neuropsychopharm 16417428

53. Argyriou A., Prast H., Philippu A., 1998. Melatonin facilitates short-term memory. Eur J Pharmacol 349159162

54. Pacchierotti C., lapichino S., Bossini L., Pieraccini F., Castrogiovanni P., Melatonin in psychiatric disorders: a review on the melatonin involvement in psychiatry, Front Neuroendocrinol. 2001 Jan; 22(1):18-32 
55. Kurtuncu M., Arslan A.D., Akhisaroglu M., Manev H., Uz T., Involvement of the pineal gland in diurnal cocaine reward in mice, Eur. J. Pharmacol. 489 (2004) 203-205

56. Lakin M.L., Miller C.H., Stott M.L., Winters W.D., Involvement of the pineal gland and melatonin in murine analgesia, Life Sci. 29 (1981) 2543-2551

57. Mantovani M., R. Pertile, J.B. Calixto, A.R. Santos, A.L. Rodrigues, Melatonin exerts an antidepressant-like effect in the tail suspension test in mice: evidence for involvement of $\mathrm{N}$-methyl- $\mathrm{d}$ -aspartate receptors and the I -arginine-nitric oxide pathway, Neurosci. Lett. 343 (2003) 1-4.

58. Longatti P., Perin A., Rizzo V., Comai S., Giusti P., Costa C.V. Ventricular cerebrospinal fluid melatonin concentrations investigated with an endoscopic technique. J Pineal Res. 2007 Mar; 42(2):113-8

59. Nunomura A., Moreira P.I., Lee H.G., Zhu X., Castellani R.J., Smith M.A., Perry G. Neuronal death and survival under oxidative stress in Alzheimer and Parkinson diseases. CNS Neurol Disord Drug Targets. 2007 Dec; 6(6):411-23 Free radical induced oxidative damage to DNA: relation to brain aging and neurological disorders. Rao KS Indian J Biochem Biophys. 2009 Feb; 46(1):9-15

60. Butterfield D.A., Castegna A., Lauderback C.M., Drake J. Evidence that amyloid $\beta$-peptide induced lipid peroxidation and its sequelae in Alzheimer's disease brain contribute to neuronal death. Neurobiol. Aging. 2002; 23:655-664

61. Chance B., Sies H., Boveris A. Hydroperoxide metabolism in mammalian organs. Physiol. Rev. 1979; 59:527-605

62. Tan D.X., Reiter R.J., Manchester L.C., Yan M.T., El-Sawi M., Sainz R.M., Mayo J.C., Kohen R., Allegra M., Hardeland R. Chemical and physical properties and potential mechanisms: melatonin as a broad spectrum antioxidant and free radical scavenger. Curr Top Med Chem. 2002 Feb; 2(2):181-97

63. Tan D.X., Manchester L.C., Terron M.P., Flores L.J., Reiter R.J. One molecule, many derivatives: a never-ending interaction of melatonin with reactive oxygen and nitrogen species? J Pineal Res. 2007 Jan; 42(1):28-42

64. Hardeland R., Tan D.X., Reite R.J., Kynuramines, metabolites of melatonin and other indoles: he resurrection of an almost forgotten class of biogenic amines. J Pineal Res 2012; 52:139-166

65. Zlotos D.P., Jockers R., Cecon E., Rivara S., Witt-Enderby P.A. MT1 and MT2 Melatonin Receptors: Ligands, Models, Oligomers, and Therapeutic Potential J. Med. Chem., 2014, 57 (8), 3161-3185

66. Reiter R.J., Paredes S.D., Korkmaz A., Manchester L.C., Tan D.X. Melatonin in relation to the "strong" and "weak" versions of the free radical theory of aging. Adv Med Sci. 2008; 53(2):119-29

67. Hardeland R. Antioxidative protection by melatonin: multiplicity of mechanisms from radical detoxification to radical avoidance. Endocrine. 2005 Jul; 27(2):119-30

68. Liu R.Y., Zhou J.N., van Heerikhuize J., Hofman M.A., Swaab D.F. Decreased melatonin levels in postmortem cerebrospinal fluid in relation to aging, Alzheimer's disease, and apolipoprotein E-epsiIon4/4 genotype. J Clin Endocrinol Metab. 1999 Jan; 84(1):323-7

69. Zhou J.N., Liu R.Y., Kamphorst W., Hofman M.A., Swaab D.F. Early neuropathological Alzheimer's changes in aged individuals are accompanied by decreased cerebrospinal fluid melatonin levels. J Pineal Res. 2003 Sep; 35(2):125-30

70. Welin A-K, Svedin P., Lapatto R., et al. Melatonin reduces inflammation and cell death în white matter în the mid-gestation fetal sheep following umbilical cord occlusion. Pediatr Res 2007; 61:153-8.

71. Yawno T., Castillo-Melendez M., Jenkin G., et al. Mechanisms of melatonin-induced protection în the brain of late gestation fetal sheep în response to hypoxia. Dev Neurosci 2012;34:543-51.

72. Supramaniam V.G., Jenkin G., Loose J., et al. Chronic fetal hypoxia increases activin A concentrations în the late-pregnant sheep. BJOG Int J Obstet Gynaecol 2006; 113:102-9.

73. Robertson N.J., Faulkner S., Fleiss B., Bainbridge A., Andorka C., Price D., Powell E., Lecky-Thompson L., Thei L., Chandrasekaran M., Hristova M., Cady E.B., Gressens P., Golay X., Raivich G. Melatonin augments hypothermic neuroprotection in a perinatal asphyxia model. Brain. 2013 Jan; 136(Pt 1):90-105
74. T. Lekic, A. Manaenko, W. Rolland et al., Neuroprotection by melatonin after germinal matrix hemorrhage in neonatal rats, Acta Neurochirurgica, no. 111, pp. 201-206, 2011

75. Fulia F., Gitto E., Cuzzocrea S., Reiter R.J., Dugo L., Gitto P., et al. Increased levels of malondialdehyde and nitrite/nitrate în the blood of asphyxiated newborns: reduction by melatonin. J. Pineal Res. 2001; 31:343-349.

76. Jaworek J., Leja-Szpak A., Bonior J., Nawrot K., Tomaszewska R., Stachura J., Sendur R., Pawlik W., Brzozowski T., Konturek S.J. Protective effect of melatonin and its precursor L-tryptophan on acute pancreatitis induced by caerulein overstimulation or ischemia/ reperfusion. J Pineal Res. 2003 Jan; 34(1):40-52

77. Seifman M.A., Adamides A.A., Nguyen P.N., Vallance S.A., Cooper D.J., Kossmann T., Rosenfeld J.V., Morganti-Kossmann M.C. Endogenous melatonin increases in cerebrospinal fluid of patients after severe traumatic brain injury and correlates with oxidative stress and metabolic disarray. J Cereb Blood Flow Metab. 2008 Apr; 28(4):684-96

78. Anders Hay-Schmidt, Niels Vrang, Philip J. Larsen, Jens D. Mikkelsen, Projections from the raphe nuclei to the suprachiasmatic nucleus of the rat, Journal of Chemical Neuroanatomy, 2003, 25, 4, 293

79. Pontes G.N., Cardoso E.C., Carneiro-Sampaio M.M., Markus R.P. (2007). Pineal melatonin and the innate immune response: the TNF alpha increase after cesarean sections suppress nocturnal melatonin production. J. Pineal Res. 43, 365-371

80. Morin L.P. Serotonin and the regulation of mammalian circadian rhythmicity. Ann. Med. 1999; 31:12-33

81. Edgar D.M., Miller J.D., Prosser R.A., Dean R.R., Dement W.C. Serotonin and the mammalian circadian system: II. Phase-shifting rat behavioral rhythms with serotonergic agonists. J. Biol. Rhythms. 1993; 8:17-31

82. Prosser R.A., Heller H.C., Miller J.D. Serotonergic phase advances of the mammalian circadian clock involve protein kinase $\mathrm{A}$ and $\mathrm{K}^{+}$ channel opening. Brain Res. 1994; 644:67-73

83. Esteban S., Garau C., Aparicio S., Moranta D., Barcelo P., Fiol M.A., Rial R. Chronic melatonin treatment and its precursor I-tryptophan improve the monoaminergic neurotransmission and related behaviorin the aged rat brain. J. Pineal Res. 2010; 48:170

84. Gannon R.L., Millan M.J. Evaluation of serotonin, noradrenaline and dopamine reuptake inhibitors on light-induced phase advances in hamster circadian activity rhythms. Psychopharmacology. 2007; 195:325-332.

85. Cuesta M., Clesse D., Pevet P., Challet E. New light on the serotonergic paradox in the rat circadian system. J. Neurochem. 2009; 110:231-243.

86. Dominguez-Lopez S., Mahar I., Bambico F. R., Labonte B., Ochoa-Sanchez R., Leyton M., Gobbi G. Short-term effects of melatonin and pinealectomy on serotonergic neuronal activity across the light-dark cycle. J. Psychopharmacol. 2012; 26:830-844.

87. Ebadi M., Govitrapong P. Neural pathways and neurotransmitters affecting melatonin synthesis. J Neural TransmSuppl 1986; 21: 125-55.

88. Axelrod J. The pineal gland: a neurochemical transducer. Science 1974; 184 (144):1341-8;

89. Reiter R.J. Pineal melatonin: cell biology of its synthesis and of its physiological interactions. Endocr Rev 1991; 12(2):151-80

90. Klein D.C., Coon S.L., Roseboom P.H., Weller J.L., Bernard M., Gastel J.A., Zatz M., luvone P.M., Rodriguez I.R., Begay V., et al. The melatonin rhythm-generating enzyme: Molecular regulation of serotonin $\mathrm{N}$-acetyltransferase in the pineal gland. Recent. Prog. Horm. Res. 1997;52:307-357.; discussion 357-308

91. Moller M., Phansuwan-Pujito P., Govitrapong P., Schmidt P. Indications for a central innervation of the bovine pineal gland with substance P-immunoreactive nerve fibers. Brain Res. 1993; 611:347-351.

92. Garcia R.A.,Afeche S.C., Scialfa J.H., do Amaral F.G., dos Santos S.H., Lima F.B., Young M.E., Cipolla-Neto J. Insulin modulates norepinephrine-mediated melatonin synthesis in cultured rat pineal gland. Life Sci. 2008; 82:108-114. 
93. Bailey M.J., Coon S.L., Carter D.A., Humphries A., Kim J.S., Shi Q., Gaildrat P., Morin F., Ganguly S., Hogenesch J.B., et al. Night/ day changes in pineal expression of $>600$ genes: Central role of adrenergic/cAMPsignaling. J. Biol. Chem. 2009; 284:7606-7622

94. Zisapel N., Egozi Y., Laudon M. Inhibition of dopamine release by melatonin: Regional distribution in the rat brain. Brain Res. 1982; 246:161-163.

95. Hamdi A. Melatonin administration increases the affinity of D2 dopamine receptors in the rat striatum. Life Sci. 1998; 63:2115-2120

96. Al-Ghoul W.M., Herman M.D., Dubocovich M.L. Melatonin receptor subtype expression in human cerebellum. Neuroreport. 1998; 9:4063-4068

97. Poirel V.J., Cailotto C., Streicher D., Pevet P., Masson-Pevet M., Gauer F. MT1 melatonin receptor mRNA tissular localization by PCR amplification. Neuro Endocrinol. Lett. 2003; 24:33-38

98. Mazzucchelli C., Pannacci M., Nonno R., Lucini V., Fraschini F., Stankov B.M. The melatonin receptor in the human brain: Cloning experiments and distribution studies. Brain Res. Mol. Brain Res. 1996; 39:117-126.

99. Wu Y.H., Zhou J.N., Balesar R., Unmehopa U., Bao A., Jockers R., van Heerikhuize J., Swaab D.F. Distribution of MT1 melatonin receptor immunoreactivity in the human hypothalamus and pituitary gland: Colocalization of MT1 with vasopressin, oxytocin, and corticotropin-releasing hormone. J. Comp. Neurol. 2006; 499:897-910.

100.Sharma R., McMillan C.R., Niles L.P. Neural stem cell transplantation and melatonin treatment in a 6-hydroxydopamine model of Parkinson's disease. J. Pineal Res. 2007; 43:245-254

101.Lin C.H., Huang J.Y., Ching C.H., Chuang J.I. Melatonin reduces the neuronal loss, downregulation of dopamine transporter, and upregulation of $\mathrm{D} 2$ receptor in rotenone-induced parkinsonian rats. J. Pineal Res. 2008; 44:205-213

102.Perry R.H., Dockray G.J., Dimaline R., Perry E.K., Blessed G., Tomlinson B.E. Neuropeptides in Alzheimer's disease, depression and schizophrenia. A post mortem analysis of vasoactive intestinal peptide and cholecystokinin in cerebral cortex. J Neurol Sci. 1981 Sep; 51(3):465-72

103.Vermeiren Y., Van Dam D., Aerts T., Engelborghs S., De Deyn P.P. Brain region-specific monoaminergic correlates of neuropsychiatric symptoms in Alzheimer's disease. J Alzheimers Dis. 2014; 41(3):819-33

104.Weinshenker D., 2008. Functional consequences of locus coeruleus degeneration in Alzheimer's disease. Curr. Alzheimer Res. 5, 342-345

105.Raskind M.A., Peskind E.R., Halter J.B., Jimerson D.C. Norepinephrine and MHPG levels in CSF and plasma in Alzheimer's disease. Arch Gen Psychiatry. 1984 Apr; 41(4):343-6.

Elrod R., Peskind E.R., DiGiacomo L., Brodkin K.I., Veith R.C., Raskind M.A. Effects of Alzheimer's disease severity on cerebrospinal fluid norepinephrine concentration. Am J Psychiatry. 1997 Jan; 154(1):25-30.

106.Whitford G.M. Alzheimer's disease and serotonin: a review. Neuropsychobiology. 1986; 15(3-4):133-42

107.Argentiero V., Tavolato B. Dopamine (DA) and serotonin metabolic levels in the cerebrospinal fluid (CSF) in Alzheimer's presenile dementia under basic conditions and after stimulation with cerebral cortex phospholipids (BC-PL). J Neurol. 1980; 224 (1):53-8.

Soininen H., MacDonald E., Rekonen M., Riekkinen P.J. Homovanillic acid and 5-hydroxyindoleacetic acid levels in cerebrospinal fluid of patients with senile dementia of Alzheimer type. Acta Neurol Scand. 1981 Aug; 64(2):101-7.

108.Mayeux R., Stern Y., Sano M. Heterogeneity and prognosis in dementia of the Alzheimer type. Bull Clin Neurosci. 1985;50:7-10

109.Raymond Chuen-Chung Chang, Andrew C.K. Law, The putative neurodegenerative links between depression and Alzheimer's disease Suthicha Wuwongse, Progress in Neurobiology 91 (2010) 362-375

110.Zhao Q.F., Tan L., Wang H.F., Jiang T., Tan M.S., Tan L., Xu W., Li J.Q., Wang J., Lai T.J., Yu J.T. J The prevalence of neuropsychiatric symptoms in Alzheimer's disease: Systematic review and metaanalysis Affect Disord. 2015 Oct 24; 190:264-271.

111. Carolyn Cidis Meltzer, Gwenn Smith, Steven T. DeKosky, Bruce G. Pollock, Chester A. Mathis, Robert Y. Moore, David J. Kupfer and Charles F. Reynolds. Serotonin in Aging, Late-Life Depression, and Alzheimer's Disease: The Emerging Role of Functional Imaging Neuropsychopharmacology (1998) 18, 407-430.

112.Zweig R.M., Ross C.A., Hedreen J.C., Steele C., Cardillo J.E., Whitehouse P.J., Folstein M.F., Price D.L. Neuropathology of aminergic nuclei in Alzheimer's disease. Prog Clin Biol Res. 1989; 317:353-65

113. Lawlor B.A. Serotonin and Alzheimer's Disease, MD Psychiatric Annals October 1990 - Volume 20 Issue 10: 567-570

114.Darvas M., Henschen C.W., Palmiter R.D. Contributions of signaling by dopamine neurons in dorsal striatum to cognitive behaviors corresponding to those observed in Parkinson's disease. Neurobiol Dis. 2014 May; 65:112-23.

115. Buddhala C., Loftin S.K., Kuley B.M., Cairns N.J., Campbell M.C., PerImutter J.S., Kotzbauer P.T. Dopaminergic, serotonergic, and noradrenergic deficits in Parkinson disease. Ann Clin Transl Neurol. 2015 Oct; 2 (10):949-59

116. Politis M., Niccolini F. Serotonin in Parkinson's disease. Behav Brain Res. 2015 Jan 15;277:136-45

117.Connolly B.S., Lang A.E. Pharmacological treatment of Parkinson disease: a review. JAMA. 2014 Apr 23-30; 311(16):1670-83

118. Gheorghe M.D. Bazele neurobiologice in farmacologice in depresie, www. emcb. ro 2003.

119. Racagni G., colab. Physiology to functionality: the brain and neurotransmitter activity. Int Clin Psychopharmacol, 1999, 14 (Suppl. 1):S3-7

120.Maes M., colab. The serotonin hypothesis of major depression. In: Bloom FF, Kupfer DJ, Psychopharmacology. The Fourth Generation of Progress New York, NY; Raven Press, 1995, 933-944.

121.Beck-Friis J., von Rosen D., Kjellman B.F., Ljunggren J-G., Wetterberg L. Melatonin in relation to body measures, sex, age, season and the use of drugs in patients with major affective disorders and healthy subjects. Psychoneuroendocrinology. 1984; 9:261-77

122.McIntyre I.M., Judd F.K., Marriott P.M., Burrows G.D., Norman T.R. Plasma melatonin levels in affective states. Int J ClinPharmacol Res. 1989; 9:159-164

123.Beck-Friis J., Kjellman B.F., Aperia B., et al. Serum melatonin in relation to clinical variables in patients with major depressive disorder and a hypothesis of a low melatonin syndrome. ActaPsychiatr Scand. 1985; 71:319-330

124.Brown R., Kocsis J.H., Caroff S., et al. Differences in nocturnal melatonin secretion between melancholic depressed patients and control subjects. Am J Psychiatry. 1985; 142:811-816

125.Li, J., et al. (2013). Circadian patterns of gene expression in the human brain and disruption in major depressive disorder. PNAS. $110(24)$

126.Comai S., Ochoa-Sanchez R., Dominguez-Lopez S., Bambico F.R., Gobbi G. Melancholic-Like Behaviors and Circadian Neurobiological Abnormalities in Melatonin MT1 Receptor Knockout Mice. Int J Neuropsychopharmacol 2015 Jan 31; 18(3)

127.Kupfer Dj, Spiker D.G., Coble P.A., Neil J.F., Ulrich R., Shaw D.H. Sleep and treatment prediction in endogenous depression. Am J Psychiatry 1981; 138:429-34.

128.Kupfer D.J. Depression and associated sleep disturbances: patient benefits with agomelatine. Eur Neuropsychopharmacol 2006; 16(suppl 5):S639-43

129.Loo H., Hale A., D'haenen H. Determination of the dose of agomelatine, a melatoninergic antidepressant and selective 5-HT2c antagonist in the treatment of major depressive disorder: a placebo controlled dose range study. Int Clin Psychopharmacol 2002; 17:239

130.Kennedy S.H., Emsley R. Placebo controlled trial of agomelatinein the treatment of major depressive disorder. Eur Neuropsychopharmacol 2006; 16:93-100

131.Khaleghipour S., Masjedi M., Ahade H., Enayate M., Pasha G., Nadery F. et al. Morning and nocturnal serum melatonin rhythm 
levels in patients with major depressive disorder: an analytical cross-sectional study. Sao Paulo Med. J. [Internet]. 2012 [cited 2015 Nov 24] ; 130( 3 ): 167-172

132.Akpınar Z., Tokgöz S., Gökbel H., et al. The association of nocturnal serum melatonin levels with major depression in patients with acute multiple sclerosis. Psychiatry Res. 2008; 161(2):253-7

133.Anton-Tay F. Pineal-brain relationships. In: Wolstenholme, GEW, Knight, J, eds. The Pineal Gland. London, England: Churchill Livingstone; 1971:213-227

134.Caspi A., Sugden K., Moffitt T.E., Taylor A., Craig I.W., Harrington H., McClay J., Mill J., Martin J., Braithwaite A., Poulton R. Influence of life stress on depression: moderation by a polymorphism in the 5-HTT gene. Science. 2003 Jul 18; 301(5631):386-9.

135.Egan M.F., et al. The BDNF val66met polymorphism affects activity-dependent secretion of BDNF and human memory and hippocampal function. Cell. 2003; 112:257-269

136.Ming G., Wong S.T., Henley J., Yuan X., Song H., Spitzer N.C., Poo M. Adaptation in the chemotactic guidance of nerve growth cones. Nature 417: 411-418, 2002.

137.Andero R., Ressler K.J. Fear extinction and BDNF: Translating animal models of PTSD to the clinic. Genes, Brain, and Behavior. 2012; 11(5):503-512.

138.Kaufman J., Yang B.Z., Douglas-Palumberi H., Grasso D., Lipschitz D., Houshyar S. et al. (2006). Brain-derived neurotrophic factor-5-HTTLPR gene interactions and environmental modifiers of depression in children. Biol Psychiatry 59: 673-680.

139.Voiculescu S.E., Rosca A.E., Zeca V. et al. Impact of maternal melatonin suppression on forced swim and tail suspension behavioral despair tests in adult offspring. Journal of medicine and life 2015; 8:202-6

140.Raison C.L., Capuron L., Miller A. (2006) Cytokines sing the blues: inflammation and the pathogenesis of depression. Review. Trends in Immunology. 27, 24-31

141.Zepf F.D., Sánchez C.L., Biskup C.S. et al. Acute tryptophan depletion - converging evidence for decreasing central nervous serotonin synthesis in rodents and humans. Acta Psychiatr Scand 2014; 129:157-9

142.Stone T.W. Endogenous neurotoxins from tryptophan. Toxicon 2001; 39:61-73 si articolul Okuda S, Nishiyama N, Saito H et al Hydrogen peroxide-mediated neuronal cell death induced by an endogenous neurotoxin, 3-hydroxykynurenine. Proc Natl Acad Sci USA 1996; 93:12553-12558

143.Vianna Monica R.M., Izquierdo Luciana A., Barros Daniela M., Walz Roger, Medina Jorge H., Izquierdo Ivan. Short- and long-term memory: differential involvement of neurotransmitter systems and signal transduction cascades. An. Acad. Bras. Ciênc.; 72( 3 ): 353-364

144.Izquierdo I., Medina J.H., Vianna M.R., Izquierdo L.A., Barros D.M. Separate mechanisms for short- and long-term memory. Behav Brain Res. 1999 Aug; 103(1):1-11.

145.Devan B.D., Goad E.H., Petri H.L., Antoniadis E.A., Hong N.S., Ko, C.H., Leblanc L., Lebovic S.S., Lo Q., Ralph M.R., Mcdonald R.J. (2001). Circadian phase- shifted rats show normal acquisition but impaired long-term retention of place information in the water task. Neurobiol. Learn. Mem. 75, 51-62.

146.Jilg A., Lesny S., Peruzki N., Schwegler H., Selbach O., Dehghani F., Stehle J.H. (2010). Tempo- ral dynamics of mouse hippocam- pal clock gene expression support memory processing. Hippocampus 20, 377-388.

147.Kondratova A.A., Dubrovsky Y.V., Antoch M.P., Kondratov R.V. (2010). Circadian clock proteins control adaptation to novel environment and memory formation. Aging (Albany NY) 2, 285-297.

148.Karakas A., Coskun H., Kaya A., Kucuk A., Gunduz B. The effects of the intraamygdalar melatonin injections on the anxiety like behavior and the spatial memory performance in male Wistar rats. Behav Brain Res 2011, 222 (1):141 - 150.

149.Amir S., Cain S., Sullivan J., Robinson B., Stewart J. (1999a) In rats, odor-induced Fos in the olfactory pathways depends on the phase of the circadian clock. Neurosci Lett 272:175-178
150.Daniel Granados-Fuentes, Alan Tseng, Erik D. A Circadian Clock in the Olfactory Bulb Controls Olfactory Responsivity Herzog + Show Affiliations The Journal of Neuroscience, 22 November 2006, 26(47): 12219-12225:

151.Hyman S.E. Diagnosing disorders. Sci Am. 2003; 289:96-103

152.Breslau N., Kessler R.C., Chilcoat H.D., Schultz L.R., Davis G.C., Andreski P. Trauma and posttraumatic stress disorder in the community: the 1996 Detroit Area Survey of Trauma. Arch Gen Psychiatry. 1998; 55:626-632.

153.Naranjo-Rodriguez E.B., Orsornio A. Ortiz, E. Hernandez-Avitia, V. Mendoza-Fernandez, A. Escobar, 2000. Anxiolytic-like actions of melatonin, 5-methoxytryptophan, 5-hydroxytryptophol and benzodiazepines on a conflict procedure. Prog Neuropsychopharmacol Biol Psychiatry 24117129

154.El Mrabet F.Z., Ouakki S., Mesfioui A., El Hessni A., Ouichou A., Pinealectomy and Exogenous Melatonin Regulate Anxiety-Like and Depressive-Like Behaviors in Male and Female Wistar Rats, Neurosciene \& Medicine, Vol. 3, 2012, pp. 394-403.

155.Guardiola-Lemaitre C., A. Lenegre, R.D. Porsolt, Combined effects of diazepam and melatonin in two tests for anxiolytic activity in the mouse, Pharmacol. Biochem. Behav. 41 (1992) 405-408

156. Brotto L.A., Barr A.M., Gorzalka B.B., Sex differences in forcedswim and open-field test behaviours after chronic administration of melatonin, Eur. J. Pharmacol. 402 (2000) 87-93.

157.Coloma F.M., Niles L.P., 1988 Melatonin enhancement of [3H]gamma-aminobutyric acid and $[3 \mathrm{H}]$ muscimol binding in rat brain. Biochem Pharmacol 3712711274

158.Rosenstein R.E., Cardinali D.P., 1986 Melatonin increases in vivo Gaba accumulation in rat hypothalamus, cerebellum, cerebral cortex and pineal gland. Brain Res 398403406

159.Roybal K., Theobold D., Graham A., et al. Mania-like behavior induced by disruption of CLOCK. Proc Natl AcadSci USA. 2007; 104(15):6406-6411.

160.Sipilä T., Kananen L., Greco D., et al. An association analysis of circadian genes in anxiety disorders. Biol Psychiatry. 2010; 67(12):1163-1170.

161.Mohseni M., Mihandoost E., Shirazi A., Sepehrizadeh Z., Bazzaz J.T., Ghazi-khansari M. Melatonin may play a role in modulation of bax and bcl-2 expression levels to protect rat peripheral blood lymphocytes from gamma irradiation-induced apoptosis. Mutat Res. 2012 Oct-Nov;738-739:19-27

162.Gorwood P. Generalized anxiety disorder and major depressive disorder comorbidity: an example of genetic pleiotropy? Eur Psychiatry. 2004; 19(1):27-33

163.Ackermann K., Plomp R., Lao O., Middleton B., Revell V.L., Skene D.J., Kayser M. Effect of sleep deprivation on rhythms of clock gene expression and melatonin in humans. Chronobiol Int. 2013 Aug; 30(7):901-9.

164.Yujnovsky I., Hirayama J,. Doi M., Borrelli E., Sassone-Corsi P. Signaling mediated by the dopamine D2 receptor potentiates circadian regulation by CLOCK: BMAL1. Proc Natl AcadSci U.S.A. 2006; 103:6386-6391

165.Andras David Nagy, Ayaka Iwamoto, Misato Kawai, RyoseiGoda, Haruka Matsuo, Tsuyoshi Otsuka, Mao Nagasawa, Mitsuhiro Furuse, Shinobu Yasuo, Melatonin adjusts the expression pattern of clock genes in the suprachiasmatic nucleus and induces antidepressant-like effect in a mouse model of seasonal affective disorder, Chronobiology International, 2015, 32, 4, 447

166.Partonen T. (2012). Clock gene variants in mood and anxiety disorders. J. Neural Transm. 119

167.Bekyarova G., Bratchkova Y., Tancheva S. (2012) Effective melatonin protection of burn-induced hepatic disorders in rats. Cent Eur J Med 7: pp. 533-538_ENREF_2

168. Ogawa S., Lubahn D., Korach K., Pfaff D., 1997. Behavioural effects of estrogen receptor gene distribution in male mice. Proc. Natl. Acad Sci U.S.A. 94, 1476 - 1481.

169.Gravance C.G., Casey P.J., Erpino M.J., 1996. Progesterone does not inhibit aggression produced by testosterone metabolites in castrated male mice. Horm. Behav. 30, 22-25 
170.Rubenstein D.R., Wikelski M., 2005. Steroid hormones and aggression in female Galapagos marine iguanas. Horm. Behav. 48, 329-341

171.Jasnow A.M., Huhman K.L., Bartness T.J., 2002. S hort days and exogenous melatonin increase aggression of male Syrian hamsters (Mesocricetusauratus). Horm. Behav. 42, 13-20

172.Gammie S.C., D’Anna K.L., Gernstein H., Stevenson S.A., 2009. Neurotensin inversely modulates maternal aggression. Neuroscience. 158, 1215-1223

173. Yu Y., Shi J., 2009. Relationship between levels of testosterone and cortisol in saliva and aggressive behaviors of adolescents. Biomed. Environ. Sci. 22, 44-49

174.Shah S N., Nyby J.G., 2010. Ghrelin's quick inhibition of androgen - dependent behaviors of male house mice (Musmusculus). Horm. Behav. 57, 291-296

175.Hume J.M., Wyn N.E., Edwards K.E., 2005. Castration reduces male testosterone, estradiol, and territorial aggression, but not paternal behaviorin biparental dwarf hamsters (Phodopus campbelli) Horm. Behav. 48, 303-310

176.Laredo S.A., Orr V.N., McMackin M.Z., Trainor B.C., The effects of exogenous melatonin and melatonin receptor blockade on aggression and estrogen-dependent gene expression in male California mice (Peromyscuscalifornicus). Physiol Behav. 2014; 128:86-91

177.Demas G.E., Polacek K.M., Durazzo A., Jasnow A.M., 2004. Adrenal hormones mediate melatonin - induced increases in aggress ion in male Siberian hamsters (Phodopus sungorus). Horm. Behav. $46,582-591$

178.Rendon N.M., Rudolph L.M., Sengelaub D.R., Demas G.E. (2015) The agonistic adrenal: melatonin elicits female aggression via regulation of adrenal androgens. Proceedings of the Royal Society B 282 (1819): 20152080 